\title{
Design and Implementation of Empower English Program Online (EEPO) for students and learners of Ho Chi Minh City University of Transport
}

\author{
Vu Thi Lan Anh, Nguyen Phuc Hung, and Ngo Thi Phuong Thao
}

\begin{abstract}
Technology and computers have affected teaching and learning English in tertiary education worldwide. It is seen as an important resource for instruction in foreign language teaching. There is a wide use of its ability to create online environments in which students can take the benefits from them. The Department of Foreign Languages (DFL) of Ho Chi Minh City University of Transport (UT-HCMC) recognizes the importance and the effectiveness of online English learning in the information technology era. Just a networked computer or smart phone, a headset and a course account, students can learn English anytime, anywhere. Online English learning can match different learning styles and use different activities. Currently, the Department is using the Social Learning software of Knowledge Transmission Publisher, with the simple content, high cost and the relatively low level compared to the required learning outcomes stipulated by Vietnam Ministry of Education and Training (MOET). The DFL wishes to build our own online English program to overcome the above disadvantages. Thus, this research paper explores teachers' and students' viewpoints on the present online program which has been used for the UT-HCMC students for the past 5 years- The Online Connected Program (OCP). The analysis of the responses to the questionnaires for teachers and students provides us with their perspectives as well as the difficulties they face when using OCP. The teachers' and students' suggestions are also collected. The findings obtained from this study will be used as the basis for designing a selfstudy online curriculum in the near future as a supplementary teaching adapted for both UT-HCMC students' needs and UTHCMC teachers' expectations. The researchers present some conclusions supported by quotations from the previous papers in an attempt to draw the research theory and practice.
\end{abstract}

Index Terms - Online Program, Elementary Level, Intermediate Level, Curriculum Content, Social Learning Software, Learning Outcomes, Computer- Assisted Language Learning (CALL).

\section{INTRODUCTION}

Due to the international power of English as the most common language used worldwide, it is favored as medium of instruction in Higher Education institutions for many reasons: Firstly, English is used as a source of accessing scientific knowledge in the students' major fields. Students need it when accessing the required information from English resources and data to do their assignments, researches and projects. Higher Education Internationalization means adopting English as an international language in Higher Education sector. In

Published on September 15, 2019

Vu Thi Lan Anh, Nguyen Phuc Hung, Ngo Thi Phuong Thao are with Ho Chi Minh city University of Transport, Ho Chi Minh city, Vietnam. today's global world, and with the help of developing technology, English has played a major role in many sectors[1]. It is very necessary for university students and graduates to follow the development of technology when learning English and communicate with the international universities over the internet. Secondly, it helps graduates of universities who have good understanding ability and fluent English to find high-quality jobs with good payment in international companies and organizations[2]. The rapid development of modern communication technologies has changed the areas of life including language teaching, language learning and language use. The application of information technology in language teaching has opened new horizons for language teachers with interactive teaching and learning environments and taking learning as a center in educational activities [3].

The foreign language policies of a country have an important influence on how additional languages are perceived, offered and learned. The policies often determine the foreign language learning in institutional contexts[4]. In Vietnam, courses of foreign languages have increased their demand recently due to global market competition because it has become a requirement in all higher education institutions. Vietnamese government's education goals related to the national foreign language policy, including mandatory English subject for elementary and secondary school, and B1 level for university graduates. The Vietnamese Government considers English language as a core skill crucial for a modern and globally connected economy. The Vietnamese Government is aware that English language education and training needs improving to catch up with other countries in the region and the world. As a response to the need to improve the foreign language capacity of Vietnamese workforce, the Vietnamese Ministry of Education and Training (MOET) has been implementing the National Foreign Languages 2020 Project (the 2020 Project) to strengthen the teaching and learning of foreign languages (primarily English) at all levels[5]. The government considers the 2020 Project as a breakthrough to improve the quality of English language learning and teaching at all education levels in Vietnam.

The ultimate goal of 2020 Project is that most Vietnamese students graduating from colleges and universities would be able to use a foreign language in their daily communication, study and work in an integrated, multi-cultural and multilingual environment. The 2020 Project was approved in September 2008 and it aims at enhancing foreign language training in the national education system from primary schools to universities. The Project expected all 
university graduates not majoring in foreign languages to reach B1 in the Common European Framework of Reference for Languages (CEFR). The English language levels which are concurrent with the CEFR were developed by the Council of Europe. These levels are A1- Beginner, A2- Pre-Intermediate, B1 - Intermediate B2, - Upper Intermediate $\mathrm{C} 1-$ Advanced or Competency and $\mathrm{C} 2-$ Proficiency[6]. Students reaching B1 can understand the main points of clear standard input on familiar matters regularly encountered in work, school, leisure, etc. They can deal with most situations likely to arise whilst travelling in an area where the language is spoken. They can produce simple connected text on topics which are familiar or of personal interest. They can describe experiences and events, dreams, hopes, and ambitions and briefly give reasons and explanations for opinions and plans. However, due to the limited hours of teaching English language face-to-face, many universities have to find their own ways to improve the language competence of their students, of which online learning has proved to be a very efficient and convenient way of satisfying the learning outcomes by the MOET.

Currently Vietnamese universities are facing the pressure to reduce the program load to shorten their training time, but graduates still have to meet the learning outcomes of specialized knowledge and language ability. In the face of the fact that specialized faculties prioritize the length of training of specialized knowledge blocks, cutting English teaching time, the English faculties at local universities must find ways to ensure students reach the block of language knowledge and skills that meet the requirements of domestic and foreign employers, while meeting the outcome of the MOET in implementing the Foreign Language Teaching and Learning Project in the National Education System 20082020 approved by the Government. It is hoped that having the extra online courses combined with traditional classes will help improve students' performance because of the revision and interaction opportunities that they present.

\section{OVER VIEW AND THE BENEFITS OF THE ONLINE ENGLISH TEACHING AND LEARNING WORLDWIDE}

Online education is vastly expanding and trying to get the place of traditional methods of teaching and learning. Pourhossein [7] states that early opportunities for learning a foreign language online were at the tertiary level at first, but with the development of technology these opportunities increased. Online learning can best be defined as the science of learning without using paper printed instructional material to deliver information for education and training. John et al [8] gave a definition for online learning as the use of the Internet to teach and learn. Therefore, online learning can be used for any subjects, especially for those which require interaction between teacher-student and studentstudent, like general English. Online learning recognizes the value of unplanned learning and the self-directness of the learner to increase learning experiences to improve learning achievement [9]. There is an increasing use of technology in educational fields. Computers and Internet are used as tools to enhance the teaching and learning process. Online learning has become an important component of education, and it is said to bring unique advantages in the learning process [10]. In many countries, the combination of traditional and online learning took place in all areas of education, including English teaching and learning [11]. Peggy et al [12] argue that online learning allows students to be centered because students can control their own learning pace, and activities can be flexible to better fit the learning style. Online language learning increases learner engagement through interaction [13].

It was in $1960 \mathrm{~s}$ that Illinois University in the United States of America planned to teach students based on technology and it connected the computers so that students can gain information on a course when they are listening to its lectures [14]. Based on a research study that was implanted in 2008 by the U.S. department of education, the use of online learning and online courses has increased up to $66 \%$ during the academic years of 2006 and 2007 either in state or private universities across the United States of America[15].

Computer technology is becoming an important component of language education, and application of technology and Computer-Assisted Language Learning (CALL) programs in the English language classroom have always been attracting the great attention of language teachers and students. Both teachers and students feel very enthusiastic about the use of new technology and CALL programs because these CALL programs empower the learner to realize that "there are multiple pathways to knowledge"[16]. With students, CALL programs can help them work privately at home without others' observation or errors made. This creates a positive effect on learner's selfesteem and sense of empowerment because the use of CALL program "encourages students to leave behind the notion that learning means rote memorization. It is about exploration and realization.”[17]. As a result, both English language teaching and learning are facilitated. Students now learn faster and easier than before by using technology. Computer based effective teaching and implementation of computational tools offer powerful, interesting and new ways of providing knowledge to students. In addition using technology by teachers has been so successful and influential to achieving the intended targets throughout the effective adoption of teaching strategies. Furthermore, technology helps in making teaching more interesting and productive. Different teaching methods both visual and auditory are adopted to an effectively teaching English in modern sense. With the spread and development of English language worldwide, it has been learned and spoken by a large number of people around the world. Technology has played a vital role and is reflected throughout the use of computer applications in classroom language. In teaching and learning English, a variety of devices are employed such as radios, TVs, CD players, computers, the internet, electronic dictionaries, audio cassettes, Power point videos, Skype, DVDs, etc. [18].

The expansion of online environments into language classrooms is now welcomed, in order to provide a potentially better teaching and learning experience. Meltem et al[19] indicate that as the face-to-face and online learning environments have been combined, the inherent strengths and weaknesses associated with both have been recognized. This combination of online environments with face-to-face 
learning is called blended learning. The aim in blended learning is to combine the benefits of these two environments in a harmonious way. The combination of a face-to-face instruction environment with an online environment within the same course allows not only capitalizing on the advantages of each but also catering for diverse learning styles and the needs of different students. Stijin et al [20] suggests that blended learning "appears to offer the opportunity to combine the best of a number of worlds in constructing a program that fits the particular needs in terms of time, space and technologies of a particular group of students or end-users".

Internet-based education is one technology that is used as a tool for transferring language teaching and learning. The computer has a significant role in teaching and learning language. The use of internet and computers is increasingly becoming more popular in English learning environments. Ahmet et al [21]claims that there are reasons why a computer is incorporated into English language classrooms. Firstly, it motivates students to interact more in their target language. Secondly, students feel less intimidated about using the target language by e- learning so they are independent in expressing themselves while doing the online tasks. Online communication increases students' thinking ability, and they feel less stressed. Finally, online learning can enable learners to interact with others speakers of the target language. Paul et al [22] claim that online communication is a possible cognitive amplifier that encourages both reflection and interaction.

\section{TEACHING AND LEARNING GENERAL ENGLISH AT UT-} HCMC

\section{A. Current situation of teaching and learning general English at UT-HCMC}

Learning English as a foreign language has become one of the national educational goals in Vietnam. It is believed that learning English will allow Vietnamese citizens to participate in the global economy and will help them to be competitive in the regional labor and the world market. In order to fulfill the National Foreign Language Project 2020 requirements, many Vietnamese higher education institutions have made the teaching of English a priority. UT-HCMC has provided face-to-face and online classes for the past 4 years as a way to improve the teaching and learning of English at present time. The Department of Foreign Languages of Ho Chi Minh City University of Transport recognizes the importance as well as the effectiveness of online English learning in the information technology era today. Just with a networked computer, a headset and a course account, students can learn English anytime, anywhere. Students can work in their own places. Online English learning can match different learning styles and use different activities. In addition, cooperation in learning English at the university is one of the advantages of e-learning. The era of technology boom, the introduction of smart phones makes access to online lectures very convenient. Therefore, online learning is gradually replacing the form of teaching on the lecture hall. The current trend of teaching and learning English domestically and abroad is a combination of direct classroom and online teaching. Some studies of the authors below show the use of online English learning programs in universities and schools in Vietnam in recent years.

There are two main aspects which can potentially influence on how a foreign language is taught and learned at tertiary level. Firstly, language policies of a country can partly decide how additional languages are perceived, provided and learned. Each country has its own characteristics in this respect, which may lead to a change in language learning outcomes. Secondly, time constraint in foreign language delivery in higher education is a reason why it is necessary to create language courses online. At UT-HCMC, the amount of teaching English time in traditional classes is very limited. With a total teaching time of 100 hours for general English, while the English language entry level of a majority of students is still far low, it is really a tough question for the Foreign Language Department of the University to help students meet the required learning outcome with such a limited amount of classroom teaching and learning. The solution that combines traditional and online teaching and learning has been used by the Department over the past 4 years and is continuing to be upgraded and improved to achieve the training objectives of Department in the future.

Currently, the Department is using the Social Learning software of Knowledge Transmission Publisher, with rather simple content and relatively low level compared to the required learning outcome set by the MOET for university graduates. Furthermore, the program costs each student 400 VND per year for accessing their own account and this is a dedicated program with a fixed content, and teachers cannot create or add new materials as expected. For those reasons, the Department has decided to design and implement a completely self-designed, self-constructed and selfimplemented online General English program to overcome the above- mentioned disadvantages.

\section{B. Necessity for the new online programme (EEPO)}

The origin for the idea of this face-to-face and online course was based on the teaching experiences of the authors of this paper. After teaching general English courses in a traditional classroom for many years, it was noted that there were fundamental underlying problems between the English language learning outcome requirement of the Minister of Education and Training and actual numbers of credits that the UT-HCMC allocates to the subject [23]. A blended learning situation allows students to have more time and opportunities to have contact with the target language, as well as allowing for the reorganization of the class time and activities. The blended learning model also calls for a change in the roles of teachers and students and requires students to become independent and autonomous learners.

The online course of the Department of Foreign Languages under construction includes many sections on grammar, vocabulary, functions and language skills at the pre-intermediate and intermediate levels. The audio component of the online course will allow learners to listen to native English speakers reading natural dialogues. The curriculum content is rich and diverse with reference sources. Not only does the content in the lecture in class can students search for materials and lectures from many 
different sources. The lessons provide guidance and practical exercises on a variety of practical and engaging topics.

EEPO uses a learning management system for delivery. This learning management system contains instructional material and content developed by the packages of learning materials developed by the lecturers of DFL and Center for Data and Information. The material in this program is designed to develop and strengthen all four language skills: listening, reading, speaking and writing. One of the advantages is that learners can replay, revisit, and revise content easier than in face-to-face settings. However, it requires a lot more from the learner who will need to be active and ambitious to be successful. The focus of this English language teaching and learning program is a taskbased formula. Outside class students can improve English language skills, including speaking as well as working on and creating their own learning space in an e-portfolio. Teachers can now dedicate more time to giving feedback and helping students in small groups and individually. The ultimate aim of this EEPO is the content appropriateness, easy-to-use program, program flexibility and technical satisfaction.

The website address (https://courses.ut.edu.vn/course/view.php?id=136) has been being built since the beginning of the year 2018. The program expectedly consists of the lessons based on Cambridge English Empowers B1 and B1+, including familiar topics like Communication, Travel, Money, Social Life, Work, Issues \& Problems, Advice \& Changes, Culture, Achievements, Values, Discoveries \& Invention, Personality and so on. Each lesson has 7 parts: Vocabulary, Grammar, Pronunciation, Listening, Speaking, Reading, and Writing. The language content of each lesson combines the one in the textbook and extends to other sources of materials, lectures in the form of songs, short films, sound samples for practicing pronunciation, games, puzzles, and other sample conversation / interview of native English speakers on a variety of practical, attractive, diversified contexts and situations. The EEPO components can not only provide each learner with the possibility of recycling at their own speed and in their own time what they have already experienced, but can also offer extra opportunities for further learning both from course-specific materials and materials from other web sources. In addition, such experiences can help the General English student to become less dependent on teachers and more self-reliant both during the course and in subsequent language learning experiences. Philip et al [24]recognizes the importance of self-learning with the statement "When students' knowledge is acquired only by receiving from the teacher, the student will become a passive receiver and will not experience the true learning process. The genuine nature of learning is through discovery of new things by themselves."

\section{METHODOLOGY AND INFORMATION COLLECTION}

Before building the new Online English Program (EEPO), the researchers of this paper did a survey on how the students and teachers thought about the presently-used Online English program- Online Connected Program (OCP).
The target population of this study constituted a sample of 230 students and 27 teachers. There was no gender difference, male and female students both participated in the study. The students came from three different academic disciplines including Logistics Management, computer software, Construction Engineering, Sea Transport Economics, Information Technology.

The teachers are currently teaching at the DFL of UTHCMC, and they have been teaching General English at least once. The selection of those students was completely random and based on accessibility. To gather data and to investigate the study questions, a questionnaire was designed and distributed to a sample of 230 students in different majors. After investigating the measures of content and face validity, the questionnaire was analyzed for the purpose of reliability. Then, the questionnaires were physically distributed to the participants. The questionnaire was used to find out what the respondents are doing or have done in the past related to the presently-used Online Program. OCP (Online Connected Program) is a drill-andpractice and dedicated program, and the program's content is $100 \%$ the same as the course book's content. For Speaking and Writing skills, the teachers are required to give feedback on students' answers while other sections (Vocabulary, Dialogue, Pronunciation, Grammar, Reading, and Listening) are automatically-corrected by the program.

The data was collected through the use of questionnaires. The questionnaires were filled and collected in September 2017 to January 2018. The questionnaires had 12 multiplechoice and short-answer questions. Questions 1-8 were used to identify teachers' or students' viewpoints on OCP. Questions 9-12 were their needs / suggestions for a selfstudy online program. Most questions are similar for both teachers' and students' questionnaires, except for question 4. Teachers' question 4 was based on the 8 criteria of the checklist mentioned above while students' question 4 was about whether the teacher's feedback / corrections for Speaking \& Writing skills in OCP were enough or not. Of the 12 questions, there are two questions about how satisfied the students and teachers with the program (Fig. 1 and Fig. 2 ), what they thought about the fee that the students had to pay annually (Fig. 3 and Fig. 4) and to what degrees the teachers and students agree to build another Online English Program to replace the presently-used OCP (Fig. 5).

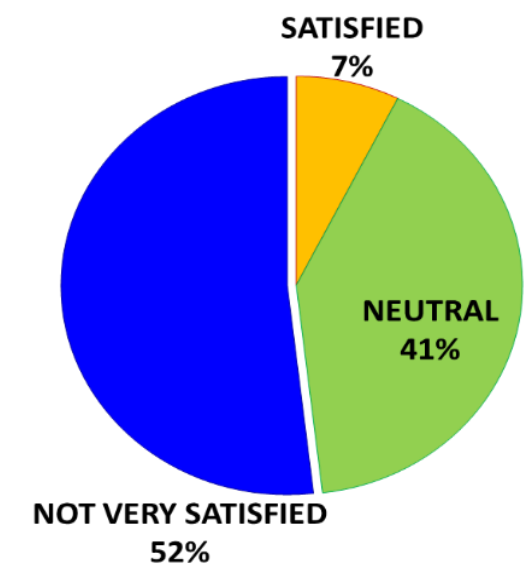

Fig.1. Teacher's satisfaction with the OCP 


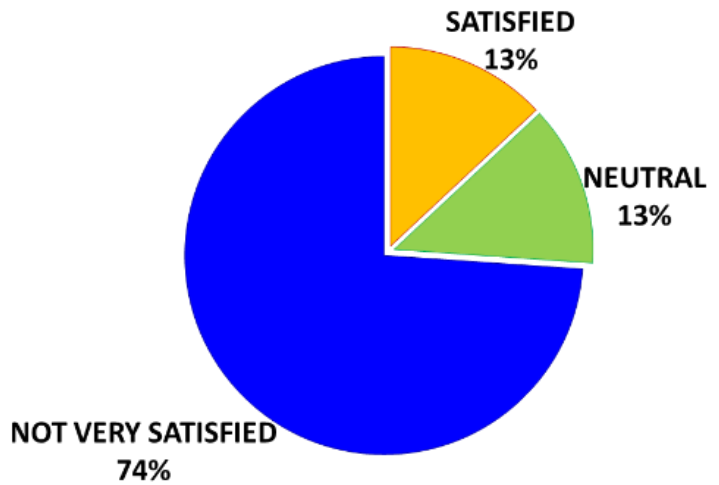

Fig .2. Students' satisfaction with the OCP

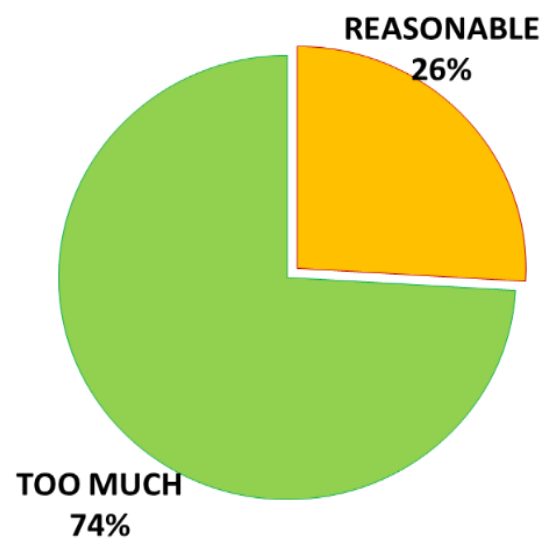

Fig. 3. Teachers' opinion about the annual fee for using the OCP

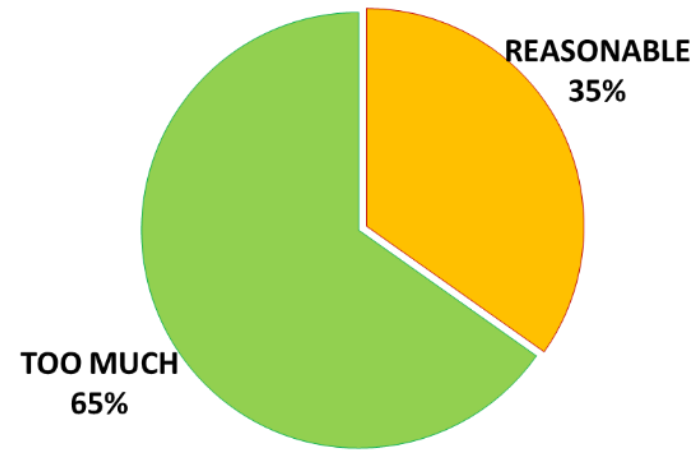

Fig. 4. Students' opinion about the annual fee for using the OCP

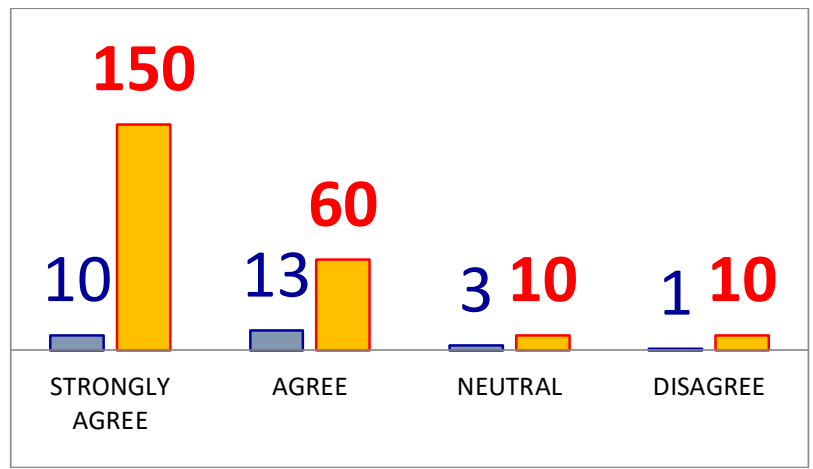

Fig. 5. The extent of agreement to building EEPO of Teachers and Students correspondingly

The DFL found from the results that the DFL should design and construct a new Online English Program to “produce materials on students' background knowledge \& culture" [25]. The EEPO is designed and constructed on Moodle. The advantages of using Moodle in English classrooms are: Moodle facilitates student-centered learning, facilitates anytime-anywhere learning, makes course administration easier and helps to reduce the cost and time of delivering instruction. It is a user-friendly tool to create E-learning or a course online as English teachers. There are several features in the Moodle system that help support and deliver instruction easier than in a traditional classroom setting.

To create a course online takes time to prepare and manage the content. The teachers who build the course agreed that an online course helped students to learn at their personal convenience and proficiency level. Students can download learning material or practice the exercise given outside the class to review their studying anytime and anywhere they want and receive feedback to show their skills immediately. Despite the trend to include less grammar in General English courses, with EEOP, it receives a lot of attention with detailed explanations and clear examples. Practically both teachers and learners want to deal with grammar as part of their courses. Learners can develop and test their own grammar rules through lots of relevant exercises. It should also be noted that despite seeming to work on grammar only, learners were developing all the language skills: Reading (when collecting banks of examples at the stage of discovering structures, for example learners were asked to read a text of their choice and find examples of the author expressing this or that communicative function, such as referring to the future); writing (in tasks and during online discussions; speaking and listening (during overview lessons in the classroom).

\section{SUMMARY AND RECOMMENDATION}

English is a compulsory subject for all UT-HCMC undergraduate students who do not meet the English language proficiency requirements stipulated by the University. Blending face-to-face teaching with an online programme has been used to improve the achievement of the students in all majors. With this combination, the DFL teachers can assign complementary resources to students to improve their learning and engage them with English outside the class. The university recognizes well that English becomes the most important means of global communication which prevents our isolation from the world, and a window to the rapid progress and development in all spheres of life. Graduates from the University require being proficient in language and they need to manage their own learning process. Crucially, students' potential future success could be severely compromised by lack of English proficiency. As a minimum, industrial employers want our graduates who are fluent at using English language to connect, communicate, and collaborate in workplace environment. This mismatches between potential employer expectations and how the university prepares students for the future workforce.

There is no doubt that General English courses in UTHCMC are unable to devote enough classroom time to facilitate the effective acquisition of a second language. General English learners typically do not get enough exposure to the language in use and they do not get enough opportunities to communicate nor to make discoveries about the language for themselves. As a result, only those learners with the motivation and opportunities to seek language 
experience outside the classroom manage to actually acquire communicative competence in the target language. Preparation for future courses is another potential benefit for General English students in relation to future academic or professional courses, which are becoming increasingly likely to be delivered using a blended learning approach.

Most teachers of DFL agree that unfamiliarity with blended learning can initially hold learners back and that the more familiar with, and enthusiastic about, blended learning the learners are at the beginning of a course the more likely they are to maximise their benefit from it. Therefore, if students do a blended learning General English course, they are more likely to gain from a subsequent English for Academic Purposes (EAP) or English for Specific Purposes (ESP) course which possibly use a blended learning approach in the near future. Making a decision to use a blended learning approach makes it more beneficial for the learners than a purely face-to-face or purely online course. But what matters most is to decide how many and which components to deliver online in a blended learning course is the likelihood of benefits for both the teacher and the learner.

As it is known that the disadvantages of using Online English program are related to technology issues such as the Internet connection, insufficient training of teachers and the effectiveness of the program itself. The learners, teachers and tutors play a key role in any blended courses. It is important to note that the teachers and tutors may need as much support in the move towards a blended approach as their learners. It may be the case that the teachers and tutors lack the computer skills their learners possess, and that this can be a daunting prospect for many and may act as a barrier to change. Moreover, online learning concerns students' motivations, challenges and interests, on one hand, and their intellectual talents on the other to learn and search in an easiest and most up to-date ways sidestepping with textbooks within which students are able to develop the interest of learning as a lifelong process.

\section{REFERENCES}

[1] Times Higher Education, "World University Rankings 2018," Times Higher Education ( $\{T H E\}), 2017$.

[2] E. Macaro, S. Curle, J. Pun, J. An, and J. Dearden, "A systematic review of English medium instruction in higher education," Lang. Teach., 2018.

[3] C. Griffiths and R. L. Oxford, "The twenty-first century landscape of language learning strategies: Introduction to this special issue," System, 2014.
[4] D. Greene and J. P. Cross, "Exploring the political agenda of the european parliament using a dynamic topic modeling approach," Polit. Anal., 2017.

[5] H. van Rensburg and T. La Thanh, "Teachers' use of facebook motivating Vietnamese students to improve their english language learning," in Education in the Asia-Pacific Region, 2017.

[6] R. E. Hamel, E. Álvarez López, and T. P. Carvalhal, "Language policy and planning: challenges for Latin American universities," Curr. Issues Lang. Plan., 2016.

[7] A. P. Gilakjani, "Factors contributing to teachers' use of computer technology in the classroom," Univers. J. Educ. Res., 2013.

[8] J. Nisbet and J. Shucksmith, Learning strategies. 2017.

[9] B. Perozzi, R. Al-Rfou, and S. Skiena, "DeepWalk: Online learning of social representations," in Proceedings of the ACM SIGKDD International Conference on Knowledge Discovery and Data Mining, 2014.

[10] J. Van Bruggen, "Theory and practice of online learning," $B r . J$. Educ. Technol., 2005.

[11] D. Nunan, "Teaching English to young learners," in Handbook of Research in Second Language Teaching and Learning, 2016.

[12] P. C. Holzweiss, S. A. Joyner, M. B. Fuller, S. Henderson, and R. Young, "Online graduate students' perceptions of best learning experiences," Distance Educ., 2014.

[13] D. Healey, "Technology Enhanced Learning Environments," in The TESOL Encyclopedia of English Language Teaching, 2018.

[14] F. J. Van Dijk, M. Bubas, and P. B. Smits, "Evaluation Studies on Education in Occupational Safety and Health: Inspiration for Developing Economies," Ann. Glob. Heal., 2015.

[15] A. C. Clifford, C. M. Doran, and K. Tsey, "A systematic review of suicide prevention interventions targeting indigenous peoples in Australia, United States, Canada and New Zealand," BMC Public Health. 2013.

[16] S. Ghavifekr and W. A. W. Rosdy, "Teaching and Learning with Technology: Effectiveness of ICT Integration in Schools," Int. J. Res. Educ. Sci., 2015

[17] V. Chandra and K. A. Mills, "Transforming the core business of teaching and learning in classrooms through ICT," Technol. Pedagog. Educ., 2015.

[18] M. Stohlmann, T. Moore, and G. Roehrig, "Considerations for Teaching Integrated STEM Education," J. Pre-College Eng. Educ. Res., 2012.

[19] M. Eryilmaz, "The Effectiveness Of Blended Learning Environments," Contemp. Issues Educ. Res., 2015.

[20] S. Van Laer and J. Elen, "In search of attributes that support selfregulation in blended learning environments," Educ. Inf. Technol., 2017.

[21] A. Basal, "The implementation of a flipped classroom in foreign language teaching," Turkish Online J. Distance Educ., 2015.

[22] P. Best, R. Manktelow, and B. Taylor, "Online communication, social media and adolescent wellbeing: A systematic narrative review," Child. Youth Serv. Rev., 2014.

[23] X. P. Nguyen, "The bus transportation issue and people satisfaction with public transport in Ho Chi Minh city," J. Mech. Eng. Res. Dev. 2019.

[24] P. H. Winne, "Self-Regulated Learning," in International Encyclopedia of the Social \& Behavioral Sciences: Second Edition, 2015 .

[25] J. Zhang, W. Xiao, S. Zhang, and S. Huang, "Device-free localization via an extreme learning machine with parameterized geometrical feature extraction," Sensors (Switzerland), 2017. 